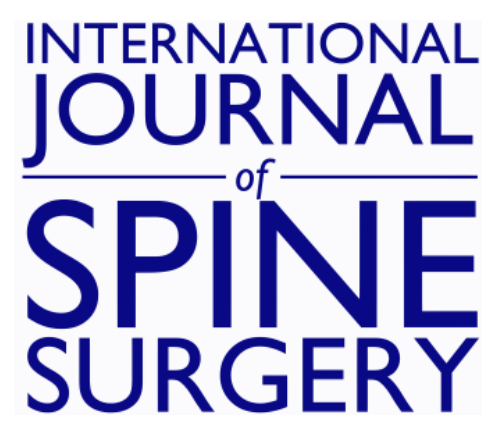

\title{
An Innovative System to Facilitate Extension Osteotomy in the Prone Position for Chin-on-Chest Deformity of Ankylosing Spondylitis
}

\author{
BENJAMIN KOLB, JOHN LARGE and GLYN SMURTHWAITE
}

Int J Spine Surg 2020, 14 (6) 1009-1015

doi: https://doi.org/10.14444/7151

http://ijssurgery.com/content/14/6/1009

This information is current as of April 26, 2023.

Email Alerts Receive free email-alerts when new articles cite this article. Sign up at:

http://ijssurgery.com/alerts

The International Journal of Spine Surgery

2397 Waterbury Circle, Suite 1,

Aurora, IL 60504, Phone: +1-630-375-1432 


\title{
An Innovative System to Facilitate Extension Osteotomy in the Prone Position for Chin-on-Chest Deformity of Ankylosing Spondylitis
}

\author{
BENJAMIN KOLB, MBCHB, FRCA, JOHN LARGE, MBCHB, BSC, GLYN SMURTHWAITE, MBCHB, BSC \\ (HONS), FRCA, FFARCS(I) \\ Department of Anaesthesia, Salford Royal NHS Foundation Trust, Salford, UK
}

\begin{abstract}
Background: In the presence of chin-on-chest deformity of ankylosing spondylitis, positioning for extension osteotomy of the spine is a challenging endeavor. Conventional prone positioning equipment cannot safely accommodate all patients with advanced deformity where the chin brow angle approaches or exceeds $90^{\circ}$. Issues such as inability to accommodate the head and associated equipment while providing operative stability and venous congestion of the head represent significant perioperative risks. The sitting position has been advocated as an alternative but is suboptimal for surgical access and anesthetic care. We present a technical note for a positioning system developed to facilitate extension osteotomy in the prone position.

Methods: A positioning device was designed to accommodate patients with advanced deformity. A series of patients with chin brow angles of up to $89^{\circ}$ were positioned using our new system.

Results: We were able to facilitate safe extension osteotomy in the prone position, for procedures lasting up to 14 hours. All our patients were discharged home without significant complication.

Conclusions: Our device is simply constructed and may be easily replicated in other institutions engaging in complex spine surgery. We hope our system provides clinicians with greater freedom to provide optimal perioperative care to their patients.
\end{abstract}

New Technology

Keywords: prone positioning, vertebral

\section{INTRODUCTION}

Ankylosing spondylitis is a progressive inflammatory joint disease associated with major sequalae including fixed ankylosis of the thoracic and cervical spine. Deformity of the thoracic cavity affects cardiorespiratory function and loss of sagittal balance along with inability to visualize the horizon impairs ambulation. Physiological impairment and functional limitation compound one another, leading to frailty, reduced quality of life, and reduced life expectancy. ${ }^{1}$ Disabling pain is common as well as malnutrition due to difficulty with chewing and swallowing.

Severe deformity often mandates surgical correction. Extension osteotomy of the cervical and thoracic spine was originally performed without general anesthesia in the sitting or lateral position. ${ }^{2,3}$ The primary mode of anesthesia was local infiltration, supplemented by inhaled nitrous oxide or intravenous barbiturate, administered at the time of instrumentation. The major determinant of this choice was cited as challenging perioperative care, including anticipated difficult intubation. Advancements such as fiberoptic intubation and neurophysiological monitoring have increased safety; however, use of the sitting position has survived these innovations. ${ }^{4}$

The sitting position is suboptimal for surgical access and anesthetic care. ${ }^{5}$ Osteotomy in the prone position was introduced, and accounts have been offered of general anesthesia for chin-onchest deformity. ${ }^{6-12}$ The use of foam blocks, bolsters, or pillows to support the patient has been described. Where the chin-brow angle approaches $90^{\circ}$ and is fixed, these means are not able to safely elevate the patient above the operating table without dangerous instability or obstruction of the abdomen.

Use of a Jackson table has been described to accommodate the head in chin-on-chest deformity. ${ }^{7}$ 

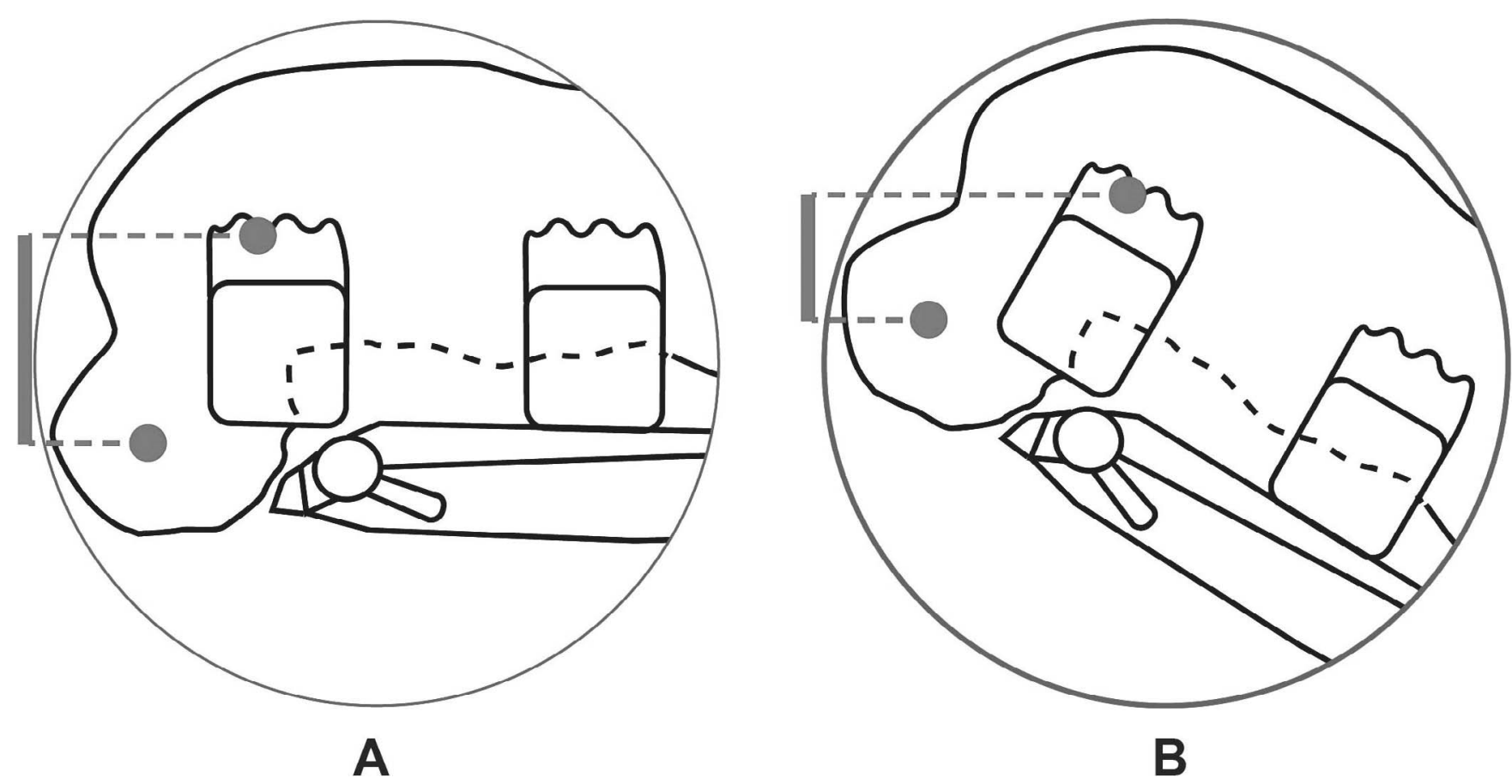

Figure 1. Critical issue with conventional positioning equipment. (A) Venous congestion due to fixed position of the head. (B) Reverse Trendelenburg capability of standard operating table insufficient to mitigate congestion.

We engage in a process of awake trial positioning for our most challenging patients. We discovered that, in advanced presentations, a critical issue arises due to the relative position of the venous drainage of the head and right atrium (Figure 1). Due to the prolonged nature of the requisite procedures, venous congestion may result in cerebral edema, airway edema, and visual loss. ${ }^{13-15}$ The steep reverse Trendelenburg orientation required to overcome this issue is not possible with a Jackson table, precluding the use of this option for our patients.

All commercially available prone positioning systems were considered, and options were trialed, such as an Allen ${ }^{\circledR}$ Advance table and Relton-Hall blocks in standard configuration and augmented using high-density polyurethane foam and operating table attachments. Lack of stability, inability to accommodate the Mayfield ${ }^{\circledR}$ clamp, and venous congestion prohibited the use of any such system. We were faced with a significant positioning conundrum demanding a creative solution.

We offer a technical report for a positioning system using the Advanced Deformity Adjustable Proning Tool (ADAPT; Figure 2). The presenting morphology of our patients positioned to date is illustrated in Figure 3A.

\section{MATERIALS AND METHOD}

\section{Positioning System}

A 3-dimensional, topographical reconstruction of our first patient was produced using infrared imaging and used to model a new positioning device (Figure 4A). The ADAPT was developed to work in conjunction with a standard operating table, augmenting reverse Trendelenburg capability (in our institution: Eschmann T20, 35\%/Maquet Alpha$\left.\operatorname{maxx}, 30^{\circ}\right)$. It was designed to provide stable operating conditions and to accommodate the head, ventilating circuit, and Mayfield frame.

The device is assembled from a set of interchangeable components and may accommodate a range of needs. It consists of a polyethylene foam body and a rigid acrylonitrile butadiene styrene plastic top. Relton-Hall supports, attached by hook and loop fastenings, are used to bridge the device and the patient's thorax and pelvis (Figure 4B).

A top component with a cutout section enabled the head to be accommodated in its fixed position. We encountered a patient with less advanced deformity that could be positioned without a cutout, but who still required use of the ADAPT to mitigate venous congestion. We found a top component without a cutout useful in this circumstance, enabling greater versatility in placement of Relton- 


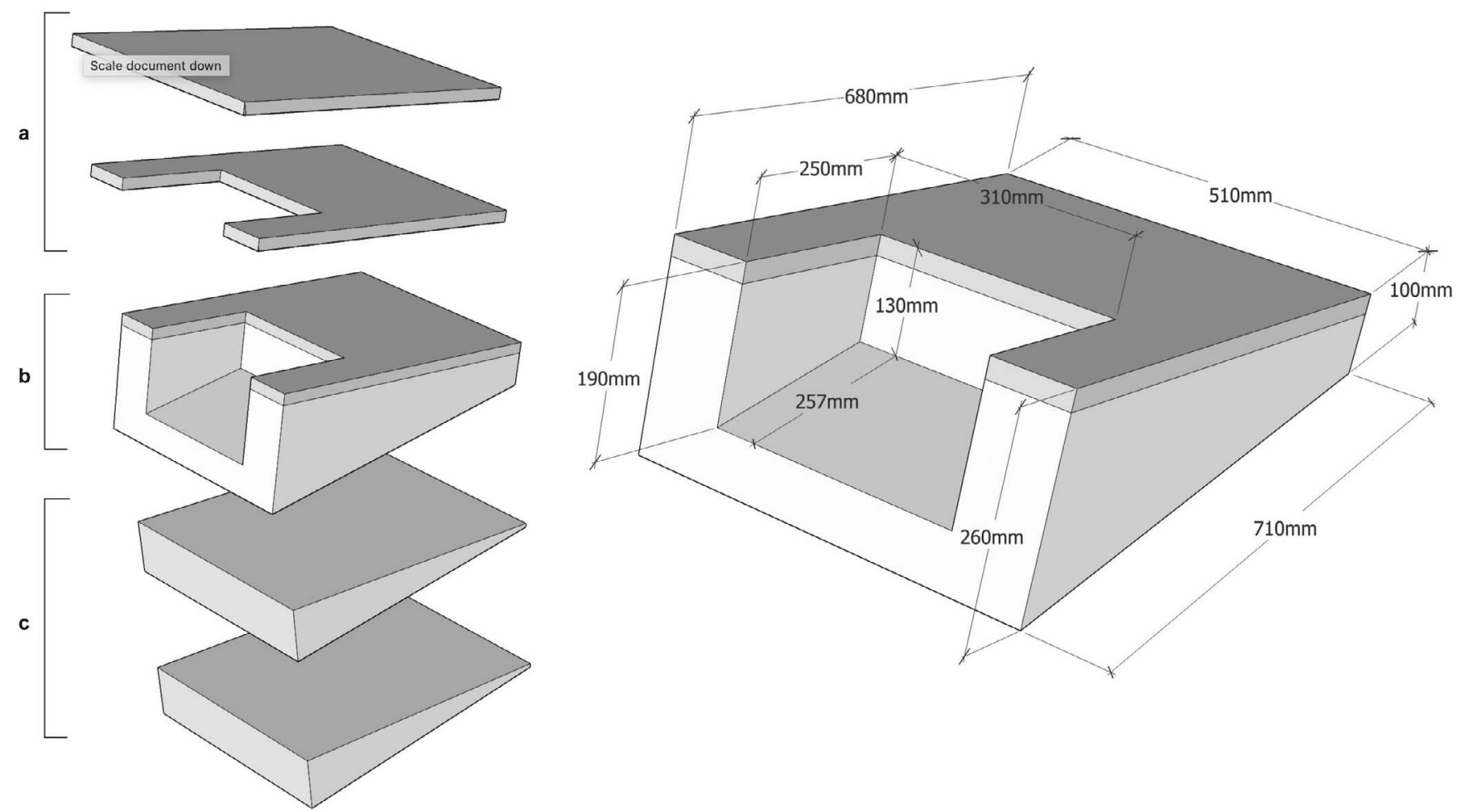

Figure 2. Advanced Deformity Adjustable Proning Tool (ADAPT). (a) Interchangeable rigid top components. (b) Polyethylene body (13 ${ }^{\circ}$ incline). (c) Incremental wedges for additional incline $\left(10^{\circ}\right.$ each).

Hall supports. Smaller foam wedges were used to provide additional inclination where necessary, attached to the main body of the device by hookand-loop fastenings. The greatest overall reverse Trendelenburg incline that we have required to date was $50^{\circ}$.

The body of the device was produced by computer numerical control milling. High-density medical grade polyethylene foam was used due to its favorable physical properties. It is inexpensive, lightweight, resistant to damage, and the overall shape does not deform under the weight of a patient over time, providing operative stability. The rigid top was vacuum formed from heat moldable thermoplastic and fit securely over the top of the polyethylene block.

At inclines of the magnitude required for our patients, instability was anticipated because of gravity. In addition to Relton-Hall supports, the knees were immobilized by gel and foam supports. A final point of contact ensured stability via a Tarlov seat applied to the patient posteriorly, which was in turn supported by a strap attached under tension to the operating table. After a successful trial positioning episode, with our patient providing feedback regarding comfort and stability, we were able to proceed confidently with this configuration.

A side effect of the steep inclination was that the surgical field was significantly elevated above ground level. A raised platform was available to ensure we could provide comfortable operating conditions for surgeons and scrub staff if necessary.

\section{Positioning Technique}

Prone positioning was performed by an experienced team consisting of 5 or more members, directed by the anesthesiologist in control of the head and airway. An appropriate positioning system configuration was determined during a preoperative visit.

The system was assembled on the operating table with the ADAPT and lower limb supports securely attached by $100-\mathrm{mm}$ Sleek ${ }^{\circledR}$ waterproof adhesive tape. The position of the Relton-Hall chest and pelvis supports was finalized before prone positioning, with the patient anaesthetized in the supine position. The operating table was oriented with Trendelenburg tilt to align the blocks with the patient, in the supine position. The patient was positioned adjacent to the operating table with the chest and anterior superior iliac spines in line with 

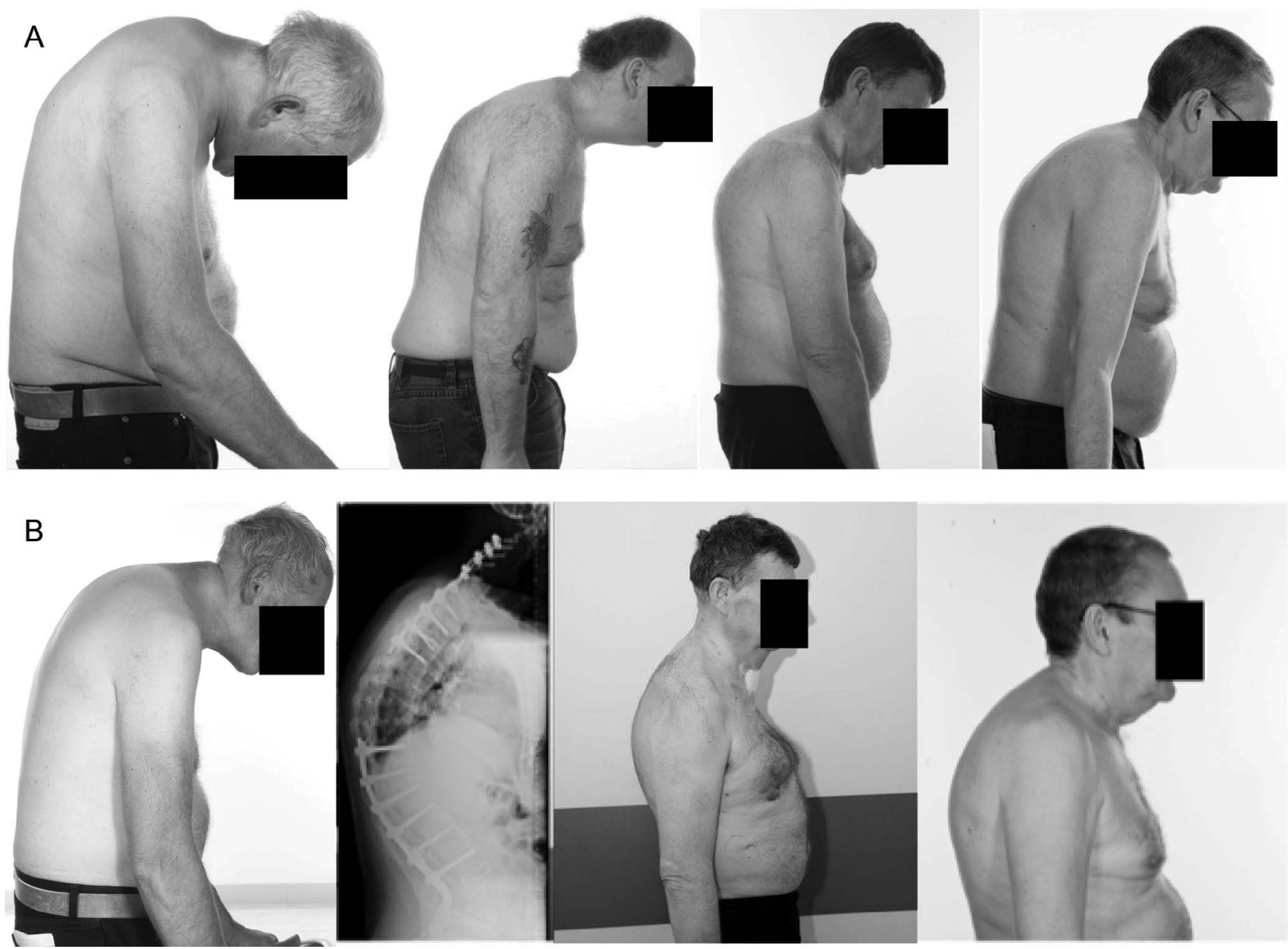

Figure 3. Patients' (A) preoperative and (B) postoperative spines.
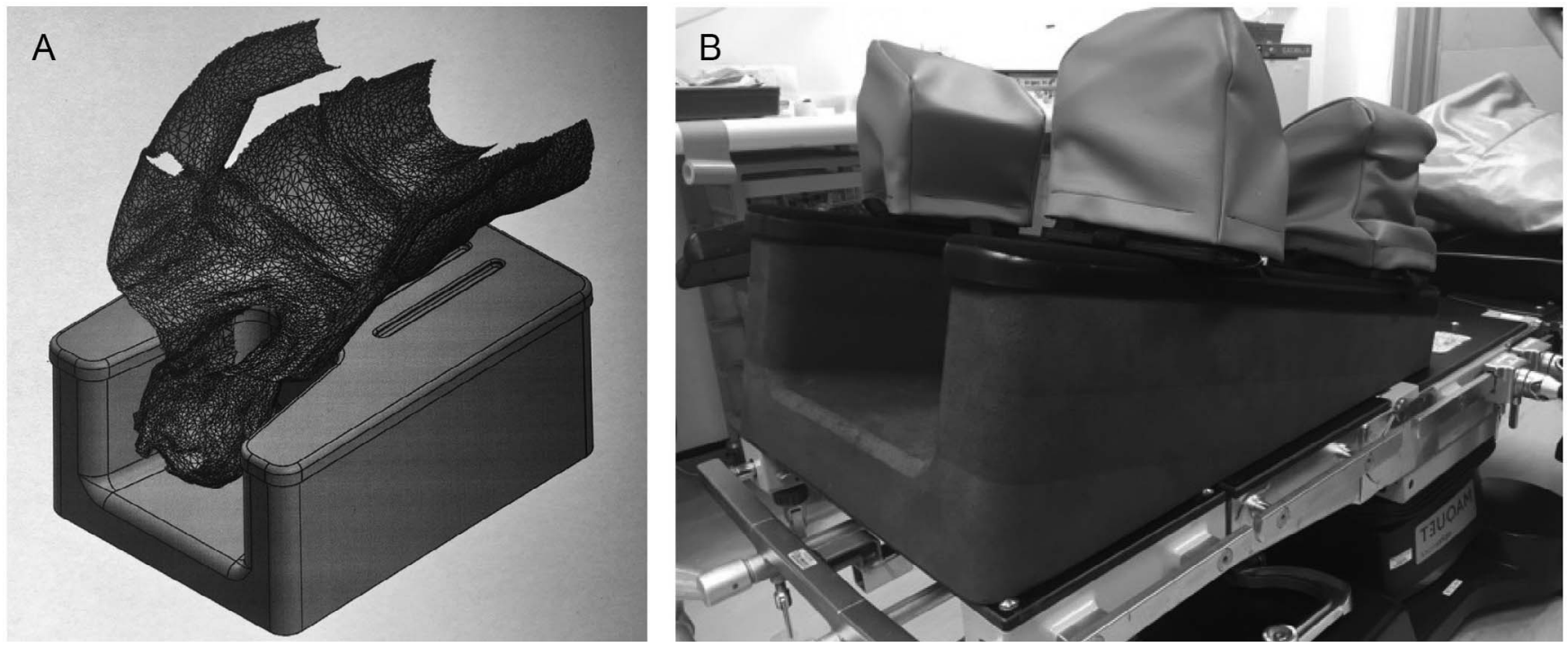

Figure 4. Positioning device design process. (A) 3-dimensional topographical reconstruction and positioning device model. (B) Manufactured device with Relton-Hall blocks attached. 

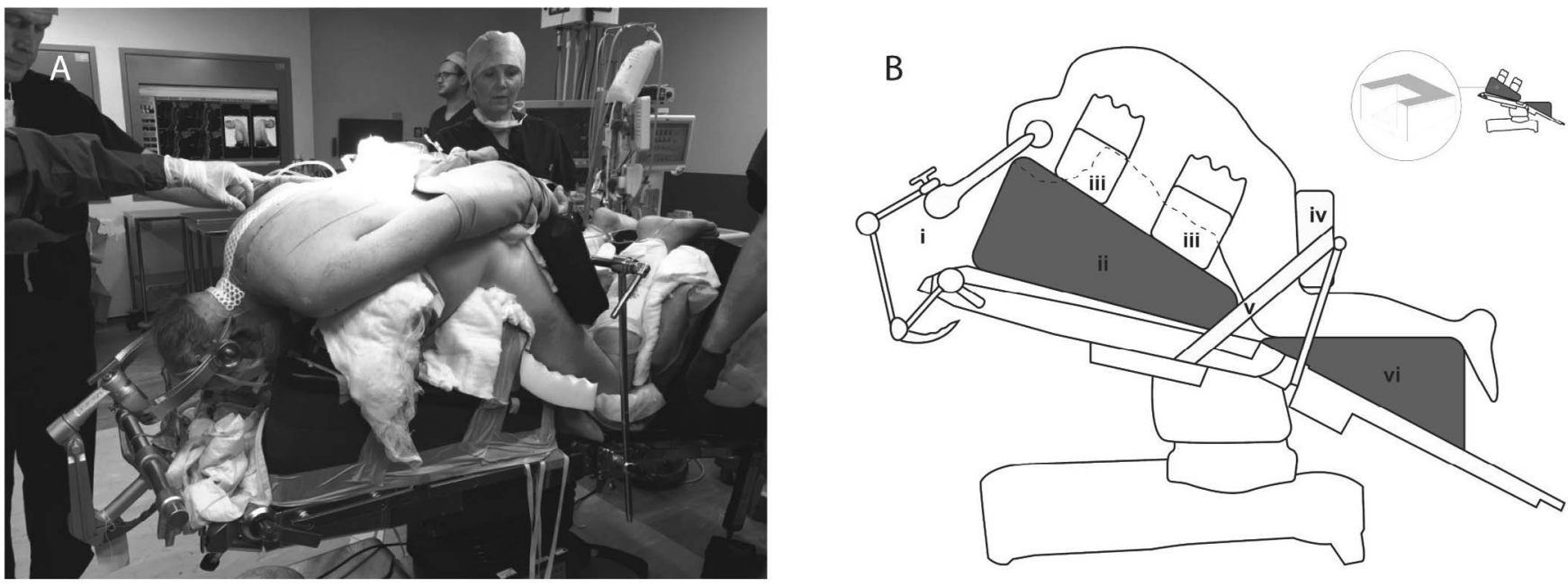

Figure 5. Positioning system configuration. (A) Patient positioned prone on positioning equipment. (B) Schematic illustration: (i) Mayfield frame, (ii) ADAPT device, (iii) Relton-Hall supports, (iv) Tarlov seat, (v) supporting strap, and (vi) gel and foam support to protect and immobilize knees.

the supports. Meticulous care was taken before prone positioning to ensure the provision of ample space to accommodate the fixed flexion deformity of the head and neck.

The patient was maneuvered onto the equipment in a logrolling fashion. The head was secured via a Mayfield clamp (applied before proning) or with a ProneView ${ }^{\circledR}$ device. Monitoring and invasive devices were checked and systemic stability ensured before minor adjustments of position were performed to free abdominal excursion. The arms were secured according to surgical requirements, either by the patient's side or above the head. Pressure areas were assessed, with particular attention to ventral weight-bearing areas, and protected with gel pads and foam. A Tarlov seat and supporting strap were applied to support the patient posteriorly.

With positing finalized, reverse Trendelenburg orientation was used to relieve venous congestion of the head and provide optimal surgical access (Figure 5B). During this process, care was taken to ensure stability, particularly with respect to prevention of caudal migration of the patient down the operating table. After meeting these prerequisites, the operations could proceed safely.

\section{RESULTS}

Details of our patients' backgrounds, their operative procedures, and outcomes can be found in the Table. Figure 5A illustrates our patient still positioned prone after successful correction of a severe chin-on-chest deformity. We have used the system described to safely facilitate surgery for 4 patients, with a maximum preoperative chin-brow angle of $89^{\circ}$. Prone positioning was safely used for a duration of up to 14 hours.

We encountered 1 instance of grade 1 pressure injury of the skin, assessed according to National Pressure Ulcer Advisory Panel criteria. ${ }^{16}$ In another case, an episode of postoperative ventilation was required due to airway edema.

Safe care was achieved in each case, with marked improvement in the postoperative chin-brow angle (Figure 3B). All patients were fit for discharge after a routine postoperative course, unaffected by complications.

\section{DISCUSSION}

\section{Complications and Limitations}

Prone positioning is associated with various physiological issues and complications that are well documented. ${ }^{13-15}$ Our position, with its unusual spatial orientation, may be subject to limitations which are not yet apparent. We consider these potential problems in the context of evidence relating to the well-established prone and jack knife positions, which are most similar.

Incidence of pressure injury of the skin in spinal surgery patients positioned prone has been cited as $23 \%$. ${ }^{17}$ The problem is commonly encountered in such patients, and we could not identify any characteristics of our system that may have contributed to the problem beyond the risk for conventional prone positioning methods.

Prolonged prone positioning is associated with airway edema, and venous congestion of the head 
Table. Patient medical histories, procedures, and outcomes.

\begin{tabular}{|c|c|c|c|c|c|}
\hline Demographics & Past History & Presentation & Procedure & Positional Injuries & Outcome \\
\hline 56 , Male & $\begin{array}{l}\text { Ankylosing spondylitis } \\
\text { Cervical spine fracture } \\
\text { NIDDM } \\
\text { Smoker } \\
\text { Paroxysmal palpitations } \\
\text { Astrocytoma } 1970 \\
\text { Poor exercise tolerance } \\
\text { BMI }=36.5\end{array}$ & $\begin{array}{l}\text { Cervical ankylosis } \\
\text { No neurology } \\
\text { Chin-brow angle } \\
\quad=89^{\circ}\end{array}$ & $\begin{array}{l}\text { Posterior cervical osteotomy } \\
\mathrm{C} 2-\mathrm{T} 6 \text { instrumentation } \\
12 \mathrm{~h} \text { prone }\end{array}$ & $\begin{array}{l}\text { Grade } 1 \text { pressure injury- } \\
\text { chest, shoulder, anterior } \\
\text { superior iliac spine }\end{array}$ & $\begin{array}{l}\text { Chin-brow angle } \\
\quad=39^{\circ} \\
\text { Discharged } 10 \mathrm{~d}\end{array}$ \\
\hline 53, Male & $\begin{array}{l}\text { Ankylosing spondylitis } \\
\text { Bilateral hip replacements } \\
\text { Good exercise tolerance } \\
\text { BMI }=26.2\end{array}$ & $\begin{array}{l}\text { Cervical and lumbar } \\
\text { ankylosis } \\
\text { Chin-brow angle } \\
=27^{\circ}\end{array}$ & $\begin{array}{l}\text { (a) Posterior L4-5 osteotomy } \\
\text { L1-S1 and Iliac } \\
\text { instrumentation } \\
14 \mathrm{~h} \text { prone } \\
\text { (b) Posterior cervical } \\
\text { osteotomy } \\
\text { C2-T5 instrumentation } \\
11 \mathrm{~h} \text { prone }\end{array}$ & $\begin{array}{l}\text { Airway edema requiring } \\
\text { surgical tracheostomy }\end{array}$ & $\begin{array}{l}\text { Chin-brow angle } \\
=\text { unknown } \\
\text { Lost to follow up } \\
\text { Discharged } 43 \mathrm{~d} \\
\quad \text { (inpatient until } \\
\text { second operation) }\end{array}$ \\
\hline 60 , Male & $\begin{array}{l}\text { Ankylosing spondylitis } \\
\text { Multiple sclerosis (relapsing } \\
\text { remitting) } \\
\text { Good exercise tolerance } \\
\text { BMI }=28.3\end{array}$ & $\begin{array}{l}\text { Thoracolumbar } \\
\text { ankylosis } \\
\text { Chin-brow angle } \\
=39^{\circ}\end{array}$ & $\begin{array}{l}\text { Circumferential lumbar } \\
\text { osteotomy } \\
\text { Posterior } \\
\text { L1-S1 and Iliac } \\
\text { instrumentation } \\
12 \text { h prone }\end{array}$ & None & $\begin{array}{l}\text { Discharged } 8 \mathrm{~d} \\
\text { Chin-brow angle } \\
\quad=12^{\circ}\end{array}$ \\
\hline 55, Male & $\begin{array}{l}\text { Ankylosing spondylitis } \\
\text { Diffuse idiopathic skeletal } \\
\text { hyperostosis } \\
\text { Previous DVT } \\
\text { Pernicious anemia } \\
\text { Gastric band } \\
\text { Significant chronic pain } \\
\text { issues } \\
\text { Thoracolumbar fixation } \\
\text { (2013) } \\
\text { Wheelchair bound } \\
\text { BMI = } 35.6\end{array}$ & $\begin{array}{l}\text { Cervicothoracic } \\
\text { ankylosis } \\
\text { Chin-brow angle } \\
=37^{\circ}\end{array}$ & $\begin{array}{l}\text { Posterior cervical osteotomy } \\
\mathrm{C} 3-\mathrm{T} 5 \text { instrumentation } \\
8 \mathrm{~h} \text { prone }\end{array}$ & None & $\begin{array}{l}\text { Discharged } 19 \mathrm{~d} \\
\text { Chin-brow angle } \\
\quad=8^{\circ}\end{array}$ \\
\hline
\end{tabular}

Abbreviations: BMI, body mass index; DVT, deep vein thrombosis; NIDDM, non-insulin dependent diabetes mellitus.

contributes to the problem. Observation of the patient's skin throughout the procedure enabled us to ensure that the incline of our position was adequate to mitigate this problem. The incidence of airway edema despite our precautions serves to illustrate the importance of the vigilance in this respect.

Complex osteotomy of the spine is associated with potential for significant blood loss, causing cardiovascular and hematological disturbances. Prone positioning may compound this effect as it is associated with a significant decrease in cardiac index, and the steep incline of our position may be disadvantageous in this sense. ${ }^{18,19} \mathrm{We}$ did not encounter any problems of this nature.

Improved lung mechanics are associated with the prone position. However, compliance decreases with an associated increase in ventilating pressures. $^{20}$ This was noted in our patients, although the clinical significance may be limited, and the steep incline may serve to mitigate the effect. ${ }^{21}$

Due to the steep incline and duration of prone positioning, we were mindful of the potential for compartment syndrome. We assessed capillary refill time and skin color of the lower limbs and planned to intermittently level the patient if these findings suggested the incidence of congestion.

Venous air embolism was also a concern, given the steep incline of our position. We considered the risk of this problem comparable to other conventional positioning methods in which there is a significant difference in height between the head and right atrium.

\section{Practical Considerations}

To accommodate the fixed position of the head, our patients were significantly elevated above the operating table. This may be problematic when the total width between the operative site and the underside of the table exceeds the capacity of the $\mathrm{C}$-arm of the intraoperative image intensifier. We did not encounter this issue, having used trial positioning to verify compatibility of the equipment.

Caudad migration down the operating table was noted during trial positioning. Where the head is secured in a Mayfield clamp, this constitutes a 
significant risk. Once identified, we were able to verify that the patient's knees were securely immobilized, and we did not encounter any problems with movement after this.

We acknowledge the limitation of the current sample size and plan to carry out a more extensive investigation into the use of our system once the data become available.

\section{CONCLUSIONS}

We present a system which enables patients with severe chin-on-chest deformity to undergo osteotomy in the prone position, facilitating optimal surgical access and safe perioperative care. The ADAPT is simply constructed and may be easily and economically replicated. Where the sitting position is still employed for complex spine surgery, we hope that our system empowers surgeons and anesthesiologists with greater freedom to provide optimal perioperative conditions for their patients suffering from advanced deformity.

\section{REFERENCES}

1. Bakland G, Gran JT, Nossent JC. Increased mortality in ankylosing spondylitis is related to disease activity. Ann Rheum Dis. 2011;70(11):1921-1925.

2. Mason C, Cozen L, Adelstein L. Surgical correction of flexion deformity of the cervical spine. Calif Med. 1953;79(3):244.

3. Urist MR. Osteotomy of the cervical spine: report of a case of ankylosing rheumatoid spondylitis. J Bone Joint Surg. 1958;40(4):833-843.

4. Simmons ED, DiStefano RJ, Zheng Y, Simmons EH. Thirty-six years experience of cervical extension osteotomy in ankylosing spondylitis: techniques and outcomes. Spine. 2006;31(26):3006-3012.

5. Langeloo DD, Journee HL, Pavlov PW, de Kleuver M. Cervical osteotomy in ankylosing spondylitis: evaluation of new developments. Eur Spine J. 2006;15(4):493-500.

6. Etame AB, Than KD, Wang AC, La Marca F, Park P. Surgical management of symptomatic cervical or cervicothoracic kyphosis due to ankylosing spondylitis. Spine. 2008;33(16):E559-E564.

7. Wollowick AL, Kelly MP, Riew KD. Pedicle subtraction osteotomy in the cervical spine. Spine (Phila Pa 1976). 2012; (37):E342-E348.

8. McMaster MJ. Osteotomy of the cervical spine in ankylosing spondylitis. J Bone Joint Surg Br. 1997;79(2):197203.

9. Mummaneni PV, Mummaneni VP, Haid RW, Rodts GE, Sasso RC. Cervical osteotomy for the correction of chin-on- chest deformity in ankylosing spondylitis. Neurosurg Focus. 2003;14(1):1-6.

10. Tokala DP, Lam KS, Freeman BJ, Webb JK. C7 decancellisation closing wedge osteotomy for the correction of fixed cervico-thoracic kyphosis. Eur Spine J. 2007;16(9):14711478.

11. El Saghir H, Boehm H. Surgical options in the treatment of the spinal disorders in ankylosing spondylitis. Clinical Exp Rheumatol. 2002; (20):S101-S105.

12. Mehdian SM, Freeman BJ, Licina P. Cervical osteotomy for ankylosing spondylitis: an innovative variation on an existing technique. Eur Spine J. 1999;8(6):505-509.

13. Edgcombe H, Carter K, Yarrow S. Anaesthesia in the prone position. Br J Anaesth. 2008;100(2):165-183.

14. DePasse JM, Palumbo MA, Haque M, Eberson CP, Daniels AH. Complications associated with prone positioning in elective spinal surgery. World J Orthop. 2015;6(3):351-359.

15. Nowicki RW. Anaesthesia for major spinal surgery. Continuing Education in Anaesthesia, Critical Care \& Pain. 2013;14(4):147-152.

16. NPIAP Pressure Injury Stages. National Pressure Injury Advisory Panel Web site. http://npuap.org/page/Pressur eInjuryStages. Accessed September 20, 2019

17. Lin S, Hey HW, Lau ET, et al. Prevalence and predictors of pressure injuries from spine surgery in the prone position. Spine. 2017;42(22):1730-1736.

18. Backofen JE. Hemodynamic changes with prone position during general anesthesia. Anesth Analg. 1985;64:194.

19. Hatada T, Kusunoki M, Sakiyama T, et al. Hemodynamics in the prone jackknife position during surgery. American J Surg. 1991;162(1):55-58.

20. Lumb AB, Nunn JF. Respiratory function and ribcage contribution to ventilation in body positions commonly used during anesthesia. Anesth Analg. 1991;73(4):422-426.

21. Pelosi P, Croci M, Calappi E, et al. The prone positioning during general anesthesia minimally affects respiratory mechanics while improving functional residual capacity and increasing oxygen tension. Anesth Analg. 1995;80(5):955960.

Disclosures and COI: The authors have no conflicts of interest or sources of funding to declare.

Corresponding Author: Benjamin Kolb, MBCHB, FRCA, Department of Anaesthesia, Salford Royal NHS Foundation Trust, Salford, UK. Phone: +44 7983475444; Email: drbkolb@ gmail.com.

Published 22 January 2021

This manuscript is generously published free of charge by ISASS, the International Society for the Advancement of Spine Surgery. Copyright (C) 2020 ISASS. To see more or order reprints or permissions, see http://ijssurgery.com. 